\title{
In memory of Professor Tatsundo Yamamoto
}

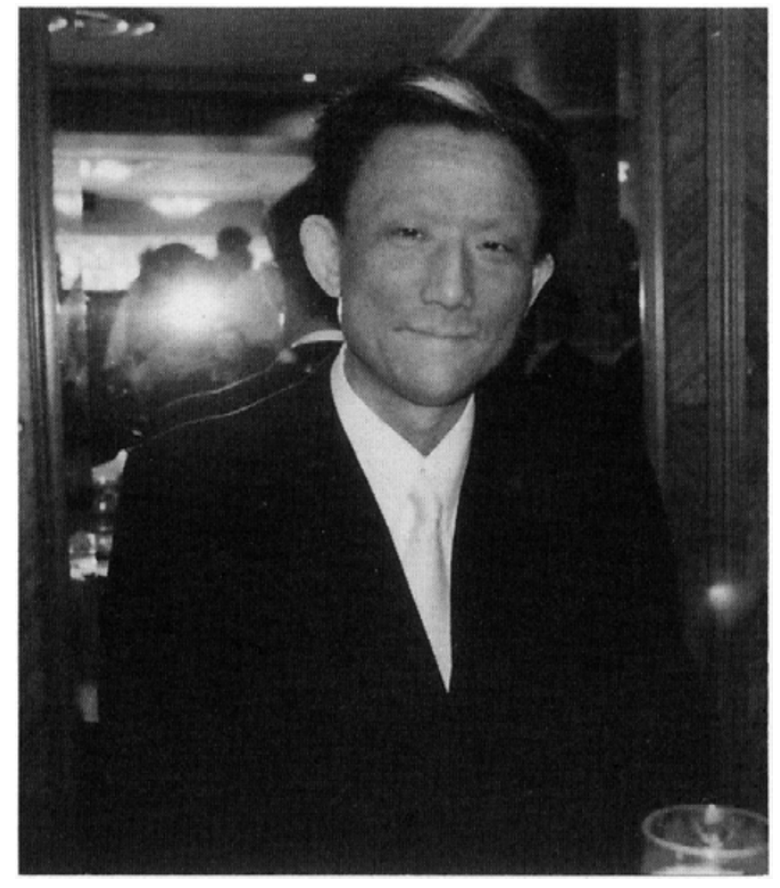

We are very sorry to have to inform you that one of the guest editors of this Mars special issue, Professor Tatsundo Yamamoto of ISAS, passed away on 20 February. He was only 41 years old and had been suffering from lymph cancer.

Most recently, Professor Yamamoto was the Project Scientist of the Planet-B mission and played a key role in defining the mission and in the design of the spacecraft. It is very unfortunate that he did not live long enough to witness the launch, scheduled for this coming July, of this Mars orbiter to which he had dedicated so much of his intellect and resources. He was also instrumental in the GEOTAIL mission where he was a leading member of the magnetometer team. He was gifted with a very quick mind and the capabilities of solving most problems with ease. His warm character appealed to everyone who worked with him, and he will be greatly missed by all who knew him and worked with him.

Professor Yamamoto was born on 10 April 1956. He graduated and received a Ph.D. from the University of Tokyo, where he became an assistant professor in 1985. He moved to ISAS in 1992 to take up the position of an associate professor and was promoted to a full professor in 1996. He is survived by his wife Yumi and two sons.

A. Nishida and K. Tsuruda 